\title{
1. Building intellectual capital for turbulent times
}

\section{THE CORE CONCERN}

We live in perilous times. Challenges highlighting the need to construct and implement societal steering mechanisms capable of operating effectively on a planetary scale are becoming increasingly urgent. The Earth is transitioning from the relatively stable and benign climate system of the Holocene to the more dynamic and turbulent climate system of the Anthropocene. The onset of the cyber age has spawned a growing array of novel needs for governance that existing institutions are poorly equipped to address. There are good reasons to expect that new infectious diseases will follow Covid-19 and that they will pose equal and potentially greater challenges on a planetary scale. And problems that have been with us for some time, like the spread of weapons of mass destruction, have not gone away.

At the same time, we are witnessing the rise of populist, nativist, authoritarian, and inward-looking regimes in societies across the world. Our attention is riveted to illiberal developments in the United States as an aging hegemon and in China as a rising superpower, simply because they are the most powerful states in the world today. But similar illiberal trends are unfolding in many other places, including Brazil, Hungary, India, Myanmar, Russia, and Turkey. It is hard to imagine a more serious disconnect between needs for governance now arising on a planetary scale and the actions of disruptive actors bent on tearing down the postwar global order without articulating any constructive plans or strategies for a more appropriate replacement.

The result is a situation that is disconcerting and more than a little frightening. Lest we succumb to gloom and doom, however, it is important to recognize that complex systems can and often do experience nonlinear changes and that these changes can give rise to unexpected and even surprising opportunities to introduce innovations. This places a premium on looking ahead in order to amass the intellectual capital needed to make the most of such opportunities when they do arise. This small book is dedicated to the proposition that a critical element of this effort will involve enhancing our understanding of the roles 
that social institutions can play in the development of steering mechanisms to meet needs for governance arising in the Anthropocene.

I have been exploring the institutional dimensions of international and global governance systems now for 50 years, starting with my early work on the rise of international regimes during the 1970s and proceeding to my more recent work on governing complex systems in the 2010s. What I have to say in this book builds on my past thinking about social institutions. But each of the chapters in the book provides a new contribution to this evolving stream of work. In a number of cases, I take issue with ideas that have achieved considerable prominence within research communities associated with the Resilience Alliance and the Earth System Governance Project and within the global change research community more generally. But in all cases, I seek to engage in a constructive dialogue with others who also are endeavoring to understand the role of institutions not only as mechanisms that can help us to meet the challenges of the Anthropocene, but also as obstacles to be overcome in order to introduce the changes needed to meet these challenges. Drafted almost entirely during the course of 2020, I offer the ideas articulated in this book in the form of reflections on planetary governance and global order during the time of Covid-19.

\section{2 \\ LOOKING AHEAD IN TROUBLED TIMES}

The last decade of the 20th century was, by and large, a time of optimism regarding the development of global order. The final collapse of the Soviet Union at the end of 1991 put an end to the Cold War. Anxieties caused by the looming threat of a nuclear war subsided quickly thereafter. The early 1990s marked the coming of age of the concern for environmental protection and sustainable development on a global scale. The United Nations Conference on Environment and Development (UNCED) in 1992 was a landmark event. Both the UN Framework Convention on Climate Change (UNFCCC) and the Convention on Biological Diversity (CBD), addressing defining challenges of the Anthropocene, were completed and signed in conjunction with UNCED. The UN Convention on the Law of the Sea (UNCLOS) entered into force in 1994. Despite the unwillingness of the United States to ratify UNCLOS, this convention has provided a constitutive framework for the development of regimes relating to human activities affecting $\sim 70 \%$ of the Earth's surface. The World Trade Organization (WTO), created under the terms of the 1994 Marrakech Agreement, commenced operations at the beginning of 1995, replacing the more ad hoc system developed under the preexisting General Agreement on Tariffs and Trade. By the 1990s, the postwar process of decolonization was largely complete, augmenting the membership of the United Nations and globalizing international society as a society of states. Many 
believed, under the circumstances, that the vision of world order as a liberal, rules-based system was within reach (Fukuyama 1992).

The contrast between the optimism of the 1990s and the sense of pessimism that has become pervasive as we enter the 2020s is hard to exaggerate. The United States, riven by internal conflict and responsive to resurgent isolationist or nativist sentiments, has lost its way as a global leader. Securitization has highlighted the role of power politics, drawing attention to the conflicts of interest among the United States, China, and Russia as they seek to maximize relative gains and jockey for political advantages in their interactions with one another. The agreements of the 1980s and 1990s limiting strategic weapons systems are expiring. The effectiveness of the WTO is challenged on a number of fronts; obstructionism on the part of the United States has even undermined the ability of the WTO's dispute settlement mechanism to function properly. Despite efforts to strengthen the governance systems for climate and biological diversity, the growing impacts of climate change have produced a global emergency, and the planet is losing species at 100-1000 times the normal or background rate. In the face of the most destructive pandemic of modern times, which many regard as a disruptive event on a par with the Great Depression and World War II, the United States withdrew support for the World Health Organization (WHO), accusing the organization of biased behavior in favor of China and depriving it of a large portion of its financial resources. ${ }^{1}$ And many ex-colonies have fallen victim to authoritarian political leaders, though they are recognized by the members of international society as sovereign states. To this litany, we may add a variety of new problems, like domestic repression, interventions in electoral systems, cyberterrorism, and cyberwarfare made possible by the onset of the cyber age. Small wonder, then, that many of us are afflicted by a sense that the progressive trends marking a large proportion of our lifetimes have now come to an end, leaving us with a growing sense of foreboding about what lies ahead.

No doubt, there are reasons to temper both of these characterizations. A critical review of the events of the 1990s reveals a darker side featuring the growth of inequality within many societies, the continuing force of systemic racism, the negative side effects of the expansion of international trade, and the failure to launch processes needed to address problems like climate change and the loss of biological diversity effectively. Conversely, a more optimistic perspective on the 2020 s reveals a decline in the frequency of conventional interstate wars, the rise of prosperous middle classes in many parts of the world, a growing awareness of the importance of coming to terms with global

\footnotetext{
1 President Biden restored US participation in the WHO as one of his first official acts.
} 
environmental issues like climate change, and an effort in many quarters to think through the requirements of pursuing sustainable development. Even so, it is easy to understand the distress arising from recent developments and the erosion of hope that accompanies the resultant sense of stress.

Taken together, these developments suggest two critical observations about the need to look ahead, even or perhaps especially in turbulent and troubled times. One observation concerns the pace of changes occurring on a global scale. The onset and spread of Covid-19 presents a particularly dramatic example. At the start of 2020, we were generally unaware of this looming threat to human well-being on a global basis. Six months later, the pandemic had upended the lives of people everywhere, disrupting economic systems and shifting the political fortunes of incumbent leaders in the process. Similarly, other major changes now spread on a planetary basis at an unprecedented rate. What this means is that we cannot afford to fixate on our current ills, wallowing in distress about day-to-day problems and paying little attention to early signs of major changes that will unfold at a rapid pace in the coming years. In this setting, there is a critical need to look ahead, not only spotting initial signs of new developments but also thinking in a wide-ranging fashion about options for coming to terms with needs for governance associated with these developments. While a preoccupation with current ills may be understandable in psychological terms, looking ahead is likely to be both healthier emotionally and more productive as a way of preparing for the challenges we will need to confront in the relatively near future.

The second observation has to do with complexity. I address complexity in more general terms in the next section. But the essential point here is that we live in a world of complex systems. Such systems are prone to nonlinear changes that regularly take us by surprise. As a result, it does not make sense to assume that current trends will unfold in a linear fashion, whether they involve positive developments like the campaign to end extreme poverty or negative developments like increases in concentrations of greenhouse gases in the Earth's atmosphere. This puts a premium on efforts to understand critical transitions and the nature of relatively modest triggers that can catalyze dramatic changes in the trajectories of largescale systems (Scheffer et al. 2009). Here, too, looking ahead is important, and all the more so in turbulent times. Rather than focusing on gradual shifts in temperatures at the Earth's surface, for example, we need to think about tipping elements that can cause sharp shifts over short periods of time (Lenton et al. 2008). Rather than thinking mainly about linear trends in the incidence of known diseases, we need to prepare for the possible eruption of new infectious diseases like Covid-19. The combination of speed and nonlinearity makes it essential to look ahead with an understanding that sharp shifts are normal and that there is much to be said 
for preparing for windows of opportunity when significant restructuring of seemingly fixed social structures suddenly becomes an option.

\section{PLANETARY COMPLEXITY}

Natural scientists have long understood the need to think about the Earth in systemic terms. We know, for example, that developments occurring anywhere on the planet (e.g., emissions of greenhouse gases, the melting of glaciers and ice sheets) will produce effects at the level of the Earth system. But social scientists have seldom thought in these planetary terms. There is an interest in the processes through which our species, which originated in Africa, spread out over time to populate all of the Earth's continents with the exception of Antarctica. Still, our thinking is typically place-based, focusing on the rise and fall of societies rooted in the biophysical conditions of specific regions. A hallmark of the onset of the Anthropocene, however, is not only the intensification of the impacts of human actions on their biophysical surroundings but also the expansion of the human enterprise to the planetary level. Where we once were able to contemplate the rise and fall of specific civilizations with little or no concern about the consequences for humans living in other parts of the Earth system (Diamond 2005), we now realize that we are engaged in activities likely to affect the fate of the species as a whole. What is more, the margin for error has become smaller and smaller when it comes to the future of humans on Earth. A sobering prospect, under these conditions, is that our ability to come to terms with the challenges arising today may have fundamental consequences for the fate of the species.

Even before the onset of the Anthropocene, complexity was a defining feature of the Earth system. What makes systems complex is a combination of hyperconnectivity, nonlinear dynamics, directional change, and emergent properties (Young 2017). Telecoupling, for example, means that events occurring in distant locations such as the melting of glaciers and ice sheets in the Antipodes and in the Himalayas can have drastic impacts on low-lying Pacific Island states endangered by sea-level rise and on farmers in East and Southeast Asia reliant on dependable supplies of water carried by the major rivers of the region. Nonlinear dynamics produce critical transitions that flip large biophysical systems from one basin of attraction to another. The data retrieved from ice cores drilled on the ice cap in Greenland, for instance, document sharp shifts in temperature occurring over a few years' time (Gertner 2019). Directional changes take the form of what systems analysts refer to as bifurcations in contrast to oscillations. Whereas oscillating systems show a tendency to go through recognizable cycles over time, systems subject to bifurcations move from one state to another without cycling back to states that resemble earlier states. The prominence of emergent properties constitutes 
a natural corollary of hyperconnectivity, nonlinearity, and directional change. The idea of emergence refers to the rise of successive states driven by the internal workings of a system that are so multidimensional that it is difficult if not impossible to anticipate the outcomes arising from the interactions of major drivers. A common way of characterizing the effects of emergence in complex systems is to say that the behavior of such systems is full of surprises.

In the human-dominated systems of the Anthropocene, all these features of complex systems are intensified. In the past, natural scientists have tended to abstract away the impact of human actions, seeking to model the behavior of the Earth's climate system or the evolution of major ecosystems, while setting aside human actions as external factors. However understandable it may be as an analytic strategy, this mode of analysis has always run the risk of missing critical features of the systems in question. In the Anthropocene, this strategy is no longer tenable. Anthropogenic emissions of greenhouse gases are now the most important driving force affecting the Earth's climate system by a large margin. Human actions play a dominant role as determinants of the fate of large ecosystems like the rainforests of the Amazon Basin. Of course, the challenges of finding ways to analyze these systems in holistic terms are daunting. But there is no alternative. Disaggregating these highly complex systems into their biophysical components and their human components and then assuming that we can simply combine the results to achieve a holistic picture of the behavior of these systems will not work. What we need is new intellectual capital that can be brought to bear to improve our understanding of the complex systems of the Anthropocene.

From the point of view of those concerned with protecting or promoting human values under these conditions, however, several things are clear already. For one thing, we are in need of governance systems that are both robust in the sense that they have the capacity to steer the actions of a variety of actors under a range of conditions and agile or nimble in the sense that they are able to adjust easily and quickly in response to nonlinear developments in complex systems. Many see a tension between these requirements. We tend to formalize institutional arrangements in order to maximize the willingness of actors to pay attention to their provisions and to construct more or less elaborate administrative arrangements to ensure that they operate smoothly under a variety of conditions. But doing so is apt to increase the difficulty of achieving agility in adjusting to changing circumstances. Adjusting formalized arrangements requires an ability to navigate more or less stringent procedures relating to the amendment of legally binding agreements. Administrative arrangements tend to become increasingly entrenched over time. One major challenge associated with governing complex systems, then, is to develop innovative procedures for reconciling the tension between robustness and agility. 
Another concern is a consequence of hyperconnectivity. In complex systems, it is hard to separate problems, so that they can be tackled discretely on a case-by-case basis. It is difficult to avoid the issue of climate change, for instance, in developing strategies to reduce the loss of biological diversity. The eruption of pandemics greatly complicates efforts to come to terms with economic issues on a global scale or to fulfill the goals articulated in the UN's 2030 Agenda for Sustainable Development. Issues relating to the global trade system quickly morph into matters of high politics as leading countries interpret the negotiation of trade agreements as exercises in soft power that can make a difference in strategic terms. All this complicates the application of normal procedures through which we seek to disaggregate issues to make it possible to tackle them on a somewhat self-contained basis. One way to think about this matter is to observe that the rise of hyperconnectivity makes it increasingly costly to operate on the basis of reductionism in the policy sphere (Young and Stokke 2020).

Similar remarks are in order regarding the matter of uncertainty. In all situations, it is an illusion to think that we can eliminate uncertainty regarding the consequences likely to flow from the choice of specific policy options. But in complex systems, uncertainty becomes a central feature of the policy process. One response to this is to highlight the precautionary principle, avoiding actions likely to take us too far into the realm of the unknown. In complex systems, however, there may be no way to avoid the necessity of making clearcut choices in the face of high levels of uncertainty. This is a source of serious concern under any circumstances. But when we are dealing with issues like climate change where the consequences of our actions will play out at the level of the Earth system as a whole, the concern becomes especially severe. If we fail to act in a timely manner or make choices that turn out to be seriously maladaptive, we may not get a second chance. The challenge of decision-making under uncertainty has confronted human societies for millennia. Now, we know a good deal more about many things than we did in the past. Paradoxically, however, when it comes to making major choices in the face of Earth system complexity, our level of understanding regarding the likely consequences of the options we face remains extremely limited.

\section{THE ROLE OF SOCIAL INSTITUTIONS}

These observations make it clear that we must devote increased time and energy to understanding and responding to what I call in this book the grand challenges of planetary governance in the 21 st century. Governance is a social function centered on the development and operation of mechanisms to steer human societies toward outcomes deemed desirable in collective terms and away from undesirable outcomes. At the core of every governance system is 
a set of institutions - formal, informal, or some combination of the two - that guide the actions of a variety of actors ranging from individuals to large corporate entities under a variety of circumstances. Accordingly, we must strive to improve our understanding of the evolution and operation of social institutions in complex systems. The goal of this book is to augment our understanding of the roles institutions play on a planetary scale. Starting with an account of the grand challenges framed in institutional terms, I seek throughout the book to sharpen our understanding of the nature of institutions, the processes through which they influence behavior, and the ways in which they evolve in response to a variety of pressures.

To set the stage for this journey, it will help to start with some general observations about social institutions. While some analysts dismiss social institutions as epiphenomena in the sense that they are surface manifestations of the underlying power structures of human societies, most of us see institutions as significant determinants of the course of events occurring in social systems and, by extension, socioecological systems. In fact, the two perspectives are not as incompatible as this initial formulation would suggest. Consider the case of structures of property rights, including various forms of private property, public property, and common property, for purposes of illustration. No doubt, the ability of individuals and especially organized interest groups to exercise power plays a significant role in determining the content of the structures of property rights that arise in specific social settings. But once a structure of property rights is fixed in place, it tends to take on a life of its own. Prevailing property rights exert a significant influence on the course of events in most settings. It is not easy even for the rich and powerful to ignore entrenched rules, to make an informal practice of bending them to serve their own interests, or to reform them in more formal terms. This is particularly true in settings in which there are many powerful individuals or interest groups whose preferences regarding matters like the contents of prevailing structures of property rights do not coincide. Structures of property rights are apt to become sticky once they are firmly in place and more or less extensive arrangements have been created to administer them on a day-to-day basis and to settle disputes regarding their application to specific situations. Efforts to introduce significant changes in prevailing structures of property rights frequently give rise to protracted political processes and often end in stalemate. In most cases, the preexisting structure remains in place, unless and until the efforts of reformers come to fruition. Nothing in this argument contradicts the proposition that an ability to exercise power effectively is an important driver of outcomes in social or socioecological systems. But neither does it undermine the proposition that institutions play a major role in determining the course of human interactions in a wide range of social settings. 
Several factors, taken together, make it hard to reach firm conclusions about the role of social institutions and, as a result, to make informed decisions regarding the creation and implementation of arrangements intended to move us toward socially desirable outcomes. For one thing, institutions are intangible. We can observe the buildings that house government offices and count the number of people who work for government agencies, for example, but we cannot see the constitution of a country like the United States as a material object. We know that the provisions of the constitution make a difference regarding the trajectory of collective decision-making, and it is understandable that individuals and interest groups expend enormous amounts of time and energy arguing about the proper interpretation of specific provisions of the constitution, mobilizing support for the interpretations they prefer, and seeking to induce courts to make rulings favoring their views. Still, we cannot see the provisions of this institutional arrangement in operation in the way that we can document the behavior of individuals or groups of people in a variety of settings.

In addition, we must deal with limited universes of cases and restricted opportunities to engage in experimentation in our efforts to understand the impacts of institutions. In extreme cases, such as the institutional provisions that define international society as a society of sovereign states, there is only a single case and virtually no opportunity to introduce adjustments on a controlled or experimental basis. But even in other domains, these restrictions are severe. We may think of categories like liberal democracies or capitalist economies as universes of cases, but it is obvious that there is so much variation among the members of these universes that efforts to construct generalizations applying to all the members of these universes are apt to end in failure. We are all familiar with experiments in which college students are asked to make choices in stylized situations that resemble collective-action problems like prisoner's dilemma or that feature principles of equity like the game known as divide the dollar. No doubt, the results of these experiments are illuminating. They have played a significant role, for example, in the rise of what we now know as behavioral economics (Kahneman 2011). But it does not take much reflection to realize that the relevance of these results to real-world situations is severely limited.

Beyond this lies the problem of complex or conjunctural causality (Ragin 1987). Whether we are thinking about the behavior of the Earth's climate system or the outcomes produced by a given electoral system, it is apparent that numerous drivers play a role and that individual drivers often interact with one another. In analyzing the role of institutions, this means that it is difficult, often impossible, to determine what proportion of the variance in outcomes can be attributed unambiguously to the influence of the institutions in question. Clearly, this does not mean that institutions are unimportant as determinants 
of the course of events in social settings. But it does mean that we need to be cautious at all times in making claims about the role of institutions. It means also that we need to avoid overconfidence in thinking that all we need to do to solve a particular problem is to make suitable adjustments in the character or content of the prevailing institutions.

When we think about the challenges of coming to terms with the problems of the Anthropocene, from avoiding uses of weapons of mass destruction to limiting the disruptive impacts of climate change and controlling misuses of cyberspace, it quickly becomes apparent that institutions can be a source of the problems we face as well as important features of strategies designed to address the problems. A prominent case in point involves the constitutive provisions of international society understood as a society of sovereign states. Frequently, we simply take it for granted that the world is organized as a society of states in which there are well-defined rules regarding requirements for membership, and the institution of sovereignty is understood to mean that member states have full control over their internal affairs and are not bound by any rules regarding their interactions with others that they have not accepted explicitly. We proceed to address a wide range of topics without asking probing questions about the fate of these constitutive arrangements.

It is possible to point to specific situations in which these arrangements do not produce perfect compliance. There are numerous instances, for example, in which powerful members of international society intervene without permission in the internal affairs of others. But in the context of this discussion, several more general observations are worthy of emphasis. For starters, the constitutive institutions of international society are socially constructed. They do not reflect natural laws. They are relatively recent in their origins, and they will not last forever. One of the goals of this book is to explore the prospects for change in the constitutive provisions of international society that may occur as we seek to confront the grand challenges of the 21 st century.

Despite the limitations imposed by the constitutive provisions of international society on the availability and effectiveness of strategies for coming to terms with the problems of the Anthropocene, there are success stories in efforts to respond to needs for governance in this setting. We have achieved some success in addressing problems by negotiating legally binding instruments, including several strategic arms limitation treaties, the Marrakech Agreement establishing the World Trade Organization, and the Montreal Protocol dealing with ozone-depleting substances. Still, as numerous observers have pointed out, efforts to solve many problems through the use of this strategy have proven ineffective. A prominent case in point is the problem of climate change where the UNFCCC and a series of supplemental agreements including the Kyoto Protocol, the Copenhagen Accord, and the Paris Climate 
Agreement have failed to put a stop to increases in concentrations of greenhouse gases in the Earth's atmosphere.

While it would be a mistake to underestimate the prospects for creating and implementing effective institutions to address specific needs for governance through the negotiation of international legally binding instruments, there is no need to put all our eggs in this basket. We are now witnessing the rise of a variety of nonstate actors and growing efforts to involve these actors in the creation of institutions designed to address problems at the planetary level. Whether we are approaching a threshold beyond which the activities of these actors will trigger the onset of a bifurcation regarding the constitutive provisions of international society is difficult to determine at this stage. But, increasingly, a range of nonstate actors make a difference with regard to the creation and implementation of institutions addressing global concerns. Sometimes, the result is the development of institutions that operate outside the framework of international legally binding instruments like the Forest Stewardship Council and the Marine Stewardship Council dedicated to the achievement of sustainable forestry practices and commercial fishing. In other cases, nonstate actors exert influence on the course of negotiations dealing with the terms of international agreements. A striking recent example involves the influence of nonstate actors on the negotiations leading to the 2016 Kigali Amendment to the Montreal Protocol mandating the phasing out of the production and consumption of hydrofluorocarbons on the grounds that they are greenhouse gases. In still other cases, states and nonstate actors form partnerships to create and implement regimes addressing specific needs for governance (Andonova 2017). It follows that any assessment of the prospects for coming to terms with the problems arising in the Anthropocene must pay careful attention to the role of nonstate actors, even in the absence of dramatic change in the character of international society.

Beyond this, it would be a mistake to dismiss discussions of more fundamental changes in the character of international society as idle fantasies. On a planetary scale, the dominance of the prevailing constitutive arrangements is a surprisingly recent development, reflecting the spread of the influence of Western social thought in the 19th and 20th centuries. There are growing indications that the intellectual dominance of the West is weakening and may decline dramatically during the course of the 21st century (Morris 2011). Rising levels of complexity on a planetary scale make it increasingly difficult to devise institutions that can address largescale problems effectively. Due to the effects of hyperconnectivity, institutions that seem to work well under one set of conditions can fail or even produce counterproductive outcomes under other conditions. Nonlinear changes can lead to sudden failures of institutions that seemed to produce satisfactory results in previous time periods. And the prominence of surprises means that we are often caught off guard by such 
limitations and failures. Under the circumstances, there is no reason to confine our thinking to the conventional repertoire of responses as we consider innovative approaches to addressing the grand challenges of governance of the 21 st century.

One implication of these observations is that the practice of institutional diagnostics, which is an imprecise enterprise under the best of circumstances, is becoming increasingly complicated as we move deeper into the Anthropocene. A common but fundamentally inadequate response to this situation is to fall back on proposals reflecting familiar recipes or formulaic prescriptions that are easy to grasp, despite the fact that they often fail to solve problems and may even lead to undesirable results in specific situations (Young, Webster et al. 2018). For example, advocates argue that the introduction of individual transferable quotas can be counted on to reduce stock depletions and increase efficiency in marine fisheries or that cap-and-trade systems surely will create incentives that will reduce reliance on technologies producing greenhouse gas emissions. The point is not that such institutional measures are never appropriate. Rather, all institutional arrangements need to be designed with a clear understanding of the complexity of the conditions likely to influence their performance in specific situations and, as a result, the need to include provisions making it possible to adjust them easily to circumstances that may change quickly or more or less dramatically. One response to this situation centers on the desirability of developing a well-stocked toolkit of institutional options and of honing our skills regarding the process of matching institutional measures with the conditions under which they are expected to operate.

\section{A GUIDE TO THE SUBSTANTIVE CHAPTERS}

The seven substantive chapters that follow all involve an effort to build intellectual capital that will help us to devise institutional arrangements that are well suited to addressing problems of planetary governance. I begin in Chapter 2 with an account of what I call the grand challenges of planetary governance in the 21st century. In my judgment, these challenges include protecting the Earth's climate system, controlling the eruption of pandemics, suppressing destructive misuses of cyberspace, and guiding the biotechnology revolution. These are all global concerns that are difficult, perhaps impossible, to address effectively within the familiar confines of international society. A discussion of the underlying nature of the challenges, the actors whose behavior is critical in each case, the behavioral mechanisms available to steer or guide their behavior, and the policy instruments available for operationalizing these mechanisms provides a set of empirical examples that can be used to ground the analytic themes of the following chapters in an ongoing effort to address substantive issues that are coming to the fore in the Anthropocene. 
Chapter 3 deals with what I call behavioral mechanisms, identifying and differentiating a number of ways in which institutions can steer or guide the actions of those who are subject to their provisions. Mainstream thinking tends to focus on the role of rules and various types of regulatory measures, giving rise to an interest in matters of compliance and enforcement and the settlement of disputes about the application of general rules to specific situations. Many institutions, especially in Western societies, do conform to this model. But this is not the only way in which institutions can guide the behavior of subjects. I investigate alternative mechanisms including what I call principles-based governance and goal-based governance. The interesting challenge in this regard is to analyze the conditions under which one or another of these mechanisms is likely to produce the best results measured in terms of their ability to come to terms with issues arising at the societal level.

In Chapter 4, I take a new look at what we mean in talking about the effectiveness of governance systems. I differentiate among constitutive effectiveness, problem-solving effectiveness, and positional effectiveness. This opens up the prospect that institutions may make a difference in shaping the character of social practices and determining who gets what, whether or not they are successful in producing solutions to specific problems. The defining features of international society treated as a society of sovereign states, for example, are highly influential in determining the options available for coming to terms with largescale problems like the control of weapons of mass destruction, the protection of the Earth's climate system, and the suppression of misuses of cyberspace. But this may serve to limit innovative responses to these problems as attention centers on the ins and outs of efforts to negotiate and implement the terms of international legally binding instruments to the exclusion of alternative ways of addressing the problems.

Drilling down on these concerns, I ask in Chapter 5 whether formalization increases the effectiveness of international instruments developed to deal with specific problems. That is, can we expect that legally binding instruments, which are widely regarded as the gold standard among international lawyers and specialists in international relations, are generally superior to more informal arrangements when it comes to solving major problems? This way of thinking assumes that informal arrangements are properly understood as underdeveloped institutions and that they should be moved toward more formalized arrangements as quickly as possible. But if the evidence fails to support this line of thinking, we may want to pay more attention to the value of relying on more informal arrangements in a variety of specific situations.

Chapter 6 takes up what I call the dark side of resilience, arguing that one of our challenges is to find ways to escape from social traps and that resilience in such situations can become part of the problem rather than part of the solution. Many see resilience as a desirable property of social systems because resilient 
systems are able to deal with a variety of perturbations by adjusting their internal features in ways that allow them to continue to function effectively and to avoid the onset of critical transitions. This line of thinking has produced numerous insights of interest to those concerned with the performance of institutions embedded in governance arrangements. But it is important to consider the flip side of resilience, looking into the ways in which societal dynamics can make traps difficult to escape or even increase their severity. A challenge for governance in such situations is to provide escape mechanisms rather than to emphasize the development of rules that can keep complex systems on an even keel.

This sets the stage for Chapter 7, which turns to what I characterize as the technological dimensions of governance. No one doubts that technological innovations constitute a major social driver, though arguments pointing to various forms of technological determinism are highly controversial. In this chapter, I address three major themes relating to the relationship between technology and governance. Is the course of technological innovation itself governable, or is technology a kind of juggernaut in the sense that we have little capacity to steer the direction and pace of innovation? Conversely, there are questions regarding the role(s) that technological innovations can play in coming to terms with needs for governance, especially those arising on a global scale like the problem of dealing with climate change. A particular concern in this realm centers on the differences between those who look to technology for solutions to problems and those who take the view that "technological fixes" are part of the problem rather than a key to solving problems. Leaving aside this fundamental question, there is much to be said about more practical roles for technology in addressing needs for governance. These include the contributions of technological innovations to identifying emerging needs for governance and moving governance systems from paper to practice once the relevant parties have agreed to their substantive provisions.

Finally, Chapter 8 tackles the question of the future of the global order on a macro scale. There has always been a sizable gap between the ideal and the actual with regard to the idea that the global order takes the form of an international society treated as a society of sovereign states. There is no reason to expect this gap to narrow during the foreseeable future. If anything, the impact of several change agents is likely to widen the gap. Individual sections of the chapter pursue this theme, looking specifically to the spread of globalization, the rise of nonstate actors, and the onset of the cyber age as forces that are stimulating significant changes in international society. The grand question concerns the extent to which these forces are likely to bring about changes of a fundamental nature in the character of the global order during the foreseeable future. The concluding section of the chapter tackles this question, noting that the constitutive institutions of international society are not immutable facts of 
life but recognizing also that institutional arrangements of this sort are often sticky and slow to change even when underlying societal realities are experiencing major shifts. The discussion deals with this critical question through the lens of complex systems, which are notable for the extent to which they feature nonlinear dynamics, directional patterns of change, and emergent properties. 